\title{
Effectiveness of Pediatric Palliative Care Education Program in Strengthening Nursing Students' Palliative Care Practices and Attitudes Toward Care of the Dying
}

\author{
Aslı Akdeniz Kudubes ${ }^{1}\left(\mathbb{D}\right.$, Dijle Ayar² (D) ilknur Bektas² (D), Murat Bektas² ${ }^{(\mathbb{C}}$ \\ ${ }^{1}$ Department of Pediatric Nursing, Faculty of Health, Bilecik Şeyh Edebali University, Gülümbe, Bilecik. \\ ${ }^{2}$ Department of Pediatric Nursing, Faculty of Nursing, Dokuz Eylul University, İnciraltı, İzmir. \\ Correspondence Author: Asli Akdeniz Kudubes \\ E-mail: asliakdeniz@hotmail.com \\ Received: $05.12 .2020 \quad$ Accepted: 06.09.2021
}

\begin{abstract}
Objective: The present study used a quasi-experimental design to determine the effectiveness of palliative care education program in strengthening nursing students' palliative care practices and attitudes toward care of the dying.

Methods: Using the GPOWER 3.0 statistical analysis software package, the sample size for each group was determined as 8 students. The study involved 39 nursing student of 4th year, including 17 students in the experimental group and 22 in the control group. A pediatric palliative care education program was applied to the intervention group through interactive learning methods. The education consisted of a 14-week program. It was delivered to the students as a 1-hour education session each week using the face-to-face teaching model. The measurements were made at the beginning of the education program and at 3 and 6 months using the data collection tools. The data was evaluated using multidimensional variance analysis, the Bonferroni modified t measure, and regression analysis.

Results: A significant difference was found among the experimental and the control group for total mean scores of the all scale. A high level, positive, and highly significant relationship was found between the education program and all scale.

Conclusion: The results of the study indicated that the pediatric palliative care education program was an effective method that could be used in educating nursing students. The study provides effective results for including pediatric palliative care nursing course to the nursing undergraduate education curriculum.
\end{abstract}

Keywords: Pediatric palliative care, interactive education, nurse, pediatrics

\section{INTRODUCTION}

Pediatric palliative care (PPC) refers to comprehensive care that begins from the time when the child is diagnosed with the disease and covers the period of grief (1). PPC is a necessary for pediatric nursing. For this reason, it is necessary to include topics related to PPC lessons to the curriculum starting from nursing undergraduate education (2). Moreover, regular evaluations should be performed to determine whether education programs for PPC in nursing education are effective. Such assessments are of significance in identifying deficiencies that arise during education, reorganizing the program, and achieving preparation for the profession (2). When nursing undergraduate education curricula in Turkey are examined, it is observed that certain universities have included PPC in their undergraduate nursing education; however, there is no standard in terms of duration and content. Furthermore the literature review indicates that study outcomes are limited in assessing the level of experience and practices of nursing students who include PPC (3). The study of Kudubes and Bektas (2019) suggests that web-based PPC program given to nursing students was effective in increasing the level of their knowledge and practices. The concept of pediatric palliative care is still confused with the concept of end-of-life care in our country. For this reason, it is very important to teach the concept of pediatric palliative care during the student period when the basics of nursing care are learned. It is thought that nursing students who learn this concept will maintain a higher quality of care in their professional lives. However, no other studies examining different methods in PPC education have been found. Thus, there exists a need for studies examining the effect of PPC education provided to nursing students on their knowledge levels and practices in our country.

One of the goals of PPC is to provide care for the child and the family during the last stage and to support the grieving time after death $(4,5)$. While a person who is approaching death or dying is experiencing her/his own pain, those around the person also experience certain emotions. The healthcare team providing care to the children in the hospital environment, especially the nurse and nursing students 
who establish the longest relationship with the children, experience this situation more frequently. Therefore, the attitudes of nursing students toward the concept of death are extremely important $(4,5)$. Although the number of studies centering on palliative care conducted in our country and abroad is high $(4,5)$, there are no studies investigating the PPC knowledge level of nursing students, their PPC practices, and their attitudes toward the care of the dying altogether. This study was conducted to determine the effectiveness of PPC education in strengthening nursing students' PPC knowledge level, PPC practices, and attitudes toward the care of the dying.

\section{METHODS}

\subsection{Ethical Considerations}

After obtaining permission from the institution where the study was conducted, ethics committee permission was obtained. The University Institutional Review Board (IRB approval number: 5162-GOA-2019/32-01) approved this study. In addition, by visiting and telling them about the purpose of the study, the written and verbal consent of students was included. Students voluntarily participated in the study. Students were involved in the study without any fear of results or retaliation

\subsection{Study Design, Setting and Sample}

The study planned a quasi-experimental design. The study was conducted between September 2019 and February 2020 with volunteering to nursing student of 4 th year who were taking pediatric nursing elective courses at the nursing faculty of a university.

The calculation of the sample size required for the study was done using the GPOWER 3.0 statistical analysis software package. The calculation was based on the study of Bhatnagar and Patel (2018) and used the post-test scores of the experimental and control groups in the mentioned study with a level of significance of 0.05 and $99 \%$ power (6). The sample size comprised of 8 individuals for each group. Accordingly, 39 nursing students who were taking the pediatric nursing elective courses were recruited into the study. Of the 39 students included in the study, 17 constituted the experimental group and 22 the control group. To avoid contamination in the study, experimental and control groups were conducted in two different elective course classes. The study did not employ a randomization method. The study recruited nursing student of 4 th year who were over 18 years and volunteering to participate in the study. In addition, control group conducted the pediatric emergency nursing elective course classes. They did not attend PPC nursing elective course classes.

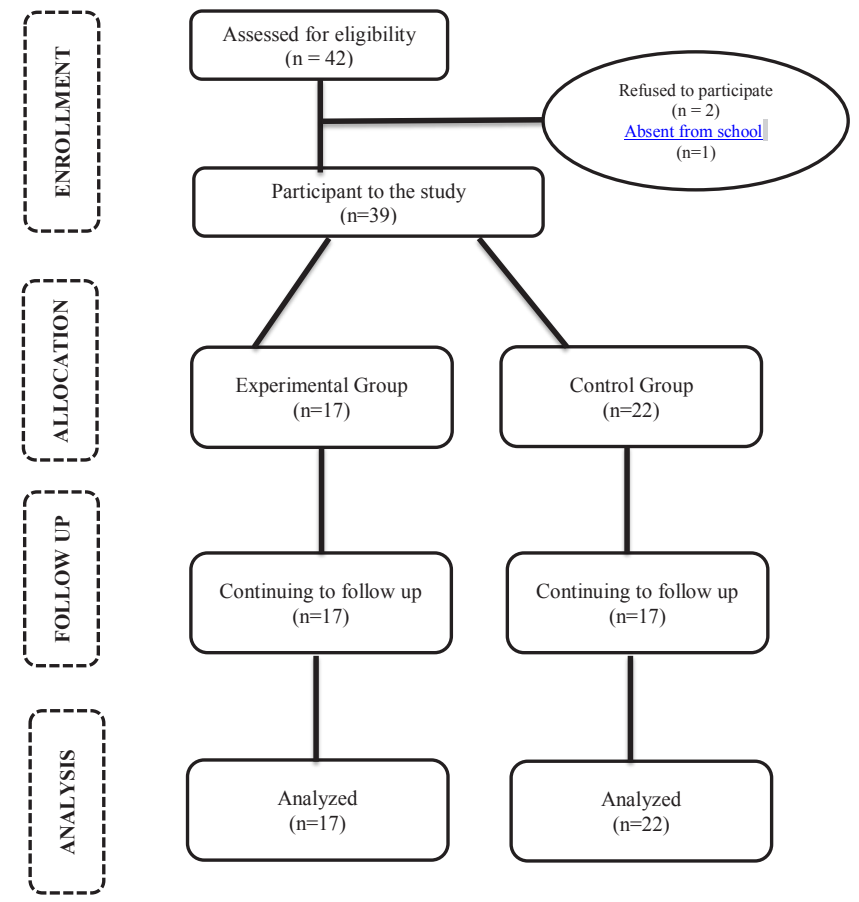

Figure I. Participant flow diagram.

\subsection{Data Collection Tools}

Students in the experimental group underwent a PPC education program that lasted 14 weeks. The measurements were made at the beginning of the education program and at 3 and 6 months using the data collection tools.

The information form consisted of four questions. The two questions collected socio-demographic information about students, such as age and gender, whereas the other two questions pertained to the students in getting information on PPC and their information sources for PPC.

The palliative care knowledge level questionnaire (PCKLQ) involves 15 questions and aims at measuring the level of students' knowledge. The questionnaire, which was designed by the authors, was created after a literature review on the PPC $(4,5,7)$. The final form was obtained after necessary improvements. The sample group of the study was composed of 346 nurses and nursing students. The development study of the questionnaire consisted of 346 nurses and nursing students. Although the questionnaire has no cut-off point, higher scores show an increased level of student knowledge. The questionnaire was submitted to the opinions of six experts. The scale was finalized after the recommendations of the experts. The grades of the six experts were analyzed using content validity analysis; the content validity index (S-CVI) was found to be 0.99 . There was a fit between the scores of the experts. Cronbach's alpha value of the questionnaire for the Turkish population was 0.793, Kaiser-Meyer-Olkin value was 0.886, and the Barlett test value was 1787.229 (8). 
The palliative care self-reported practices scale (PCSPS) is a self-reporting scale that evaluates the status of nurses' implementation of palliative care practice in the clinical setting (9). The scale consists of 18 items and 6 subdimensions, including dying-phase care (items 1-3), patient and family centered care (items 4-6), pain (items 7-9), delirium (items 10-12), dyspnea (items 13-15), and communication (items 16-18). PCSPS is a scale evaluated over total points. Higher scores received from the scale suggest improved procedures for palliative treatment. The Turkish scale validity and reliability analysis was performed in 2019 by Kudubeş et al. Cronbach's alpha $(\alpha)$ coefficients for the six sub-dimensions of the Turkish form were found to be $0.85,0.91,0.72,0.89$, 0.71 , and 0.78 , respectively. The $\alpha$ value for the overall scale was $0.91(8)$.

The Frommelt Attitudes Toward Care of the Dying Scale (FATCOD) is a 30-item scale designed by Katherine H. Murray Frommelt in 1988. The scale contains an equal number of expression including desirable and undesirable attitudes. The total score is calculated by inverting the items containing negative attitudes and summing them with the scores of responses containing positive attitudes. The higher scores indicate increased positive attitudes. Çelik and Kav performed a validity and reliability review of the scale in Turkey in 2013 and $\alpha$ value was 0.73 (10).

The PPC Education Program which contains information about PPC nursing, was created by the researchers after a literature review on the topic $(2,4,5,7)$. For its content, the education program was submitted to the opinions of experts including Department of Pediatric Oncology, Pediatric Nursing, Oncology Nursing.

The program consisted of a 14-week education module that contained introduction to PPC education program and administration of the pre-tests, definition, and purpose of the PPC, individuals involved in team, nursing and symptom management in PPC, (mucositis, changes in the blood, fatigue, sleep disorders, anorexia, nausea-vomiting, excretory changes, skin reactions, and psychosocial changes), communication in PPC, ethical and legal dimensions of PPC, spiritual care of the children and the family, end-of-life care, and complementary and alternative medicine (CAM) applications in PPC (Table 1).

\subsection{Implementation of the Education Program}

The education consisted of a 14-week program. It was delivered to the students as a 1-hour education session each week using the face-to-face teaching model. Interactive teaching methods, ensuring student participation, were used in each module. In each module, in-class group discussions on the topic were held, and concept maps were created with the nursing students. A machine-readable optical mark that provides information about the object to which it is connected is the QR code (Quick Response code). Using square codes, resources for PPC were shared with the students. Besides, for module centering on the roles and responsibilities of nurses working in the PPC unit, an interview was held with the nurse working in the PPC unit. In the module focusing on communication with the PPC patient and the family, an interview was conducted with the parent of the child who was receiving PPC. Participants in these interviews talked on the subject and answered the questions of students (Table 1).

\subsection{Data Analysis}

In order to determine the descriptive data, mean scores and percentage calculations were used. Two-way repeated measure ANOVA analysis was used in repeated measurements to compare mean scores on the PCKLQ, FATCOD, and PCSPS. In the advanced analysis of the difference between the mean scores of the PCKLQ, FATCOD, and PCSPS, one-way ANOVA analysis was used in repeated measurements to compare the mean scores of groups within the groups, and the Bonferroni adjusted t test were used to compare the control and experimental groups with each other. In order to analyze the data, the coding of the training program is " 1 " for the students in the experimental group and " 0 " for the students in the control group. The relationship between the education and PCKLQ and the relationship between PCSPS and FATCOD were analyzed using Spearman's correlation analysis. Linear regression analysis was employed to analyze the extent to which the education could predict the difference in PCKLQ, PCSPS, and FATCOD. Tolerance and variance inflation factor (VIF) values were employed to determine the existence of multicollinearity between the education and PCKLQ, PCSPS, and FATCOD, and to decide whether regression analysis could be administered to the variables. The power and the effect size of the study were calculated based on the regression analysis. G-Power 3.1 program was used to calculate the effect size with regression analysis and the calculated effect size was indicated with $\mathrm{f}^{2}$. The significance level was accepted as 0.05 .

\section{RESULTS}

Examination of descriptive characteristics of nursing students indicated that the mean age of the students in the experimental group was $21.53+0.94$, and that of students in the control group was $21.36+0.65$. Of the students in the experimental group, $88.2 \%$ were females, $64.7 \%$ were found to have received information about PPC, and $35.3 \%$ were determined to have learned about PPC from books and journals. On the contrary, $86.4 \%$ of students in the control group were females, $54.5 \%$ were determined to have received information about PPC, and $31.8 \%$ were found to have learned about PPC from books and magazines, congresses and seminars, and the Internet. Based on these analyses, the groups were observed to show no difference in terms of gender, receiving information about $\mathrm{PPC}$, and information sources about PPC. Accordingly, the groups were determined to be homogeneous $(p>0.05)$. 
Table 1. Education Modules

\begin{tabular}{|c|c|c|c|}
\hline & & Content & Methods \\
\hline $\overrightarrow{\underline{\Delta}}$ & $\begin{array}{l}\text { Introduction to PPC } \\
\text { training program and } \\
\text { administration of pre-tests }\end{array}$ & Explaining the purpose of the training program & Presentation \\
\hline$\stackrel{N}{\nu}$ & PPC and nursing & $\begin{array}{l}\text { Introducing the purpose of PPC, } \\
\text { Discussing PPC services and their current status in the world and in Turkey, } \\
\text { Learning about the staff in the PPC team and their responsibilities }\end{array}$ & $\begin{array}{c}\text { Presentation, In-class group } \\
\text { discussion }\end{array}$ \\
\hline$\frac{m}{\frac{\omega}{z}}$ & $\begin{array}{l}\text { The roles and } \\
\text { responsibilities of nurses } \\
\text { working in the PPC unit- } \\
\text { Interactive sharing }\end{array}$ & $\begin{array}{l}\text { Defining PPC nursing, } \\
\text { Discussing the duties and responsibilities of the PPC nurse }\end{array}$ & $\begin{array}{l}\text { Presentation, In-class group } \\
\text { discussion, Panel with the nurse } \\
\text { working in the related unit }\end{array}$ \\
\hline 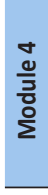 & $\begin{array}{l}\text { Management of pain, } \\
\text { fatigue, and sleep } \\
\text { disorders in PPC }\end{array}$ & $\begin{array}{l}\text { Identifying symptoms, } \\
\text { Explaining the influencing factors and the etiology, } \\
\text { Knowing the assessment methods of the symptoms, } \\
\text { Discussing pharmacological and non-pharmacological approaches to symptoms, } \\
\text { Determining appropriate nursing interventions toward symptoms }\end{array}$ & $\begin{array}{l}\text { Presentation, Case scenario, In- } \\
\text { class group discussion, Concept } \\
\text { map, QR code application, Nursing } \\
\text { care plan }\end{array}$ \\
\hline $\begin{array}{l}\frac{10}{0} \\
\frac{0}{5} \\
\frac{0}{2}\end{array}$ & $\begin{array}{l}\text { Mucositis, anorexia- } \\
\text { cachexia, and } \\
\text { management in PPC }\end{array}$ & $\begin{array}{l}\text { Identifying symptoms, } \\
\text { Explaining the influencing factors and the etiology, } \\
\text { Knowing the assessment methods of the symptom, } \\
\text { Discussing pharmacological and non-pharmacological approaches to symptoms, } \\
\text { Determining appropriate nursing interventions toward symptoms }\end{array}$ & $\begin{array}{l}\text { Presentation, Case scenario, In- } \\
\text { class group discussion, Concept } \\
\text { map, QR code application, Nursing } \\
\text { care plan }\end{array}$ \\
\hline $\begin{array}{l}\circ \\
\frac{0}{5} \\
\frac{0}{\Sigma} \\
\Sigma\end{array}$ & $\begin{array}{l}\text { Nausea-vomiting, and } \\
\text { diarrhea-constipation and } \\
\text { management in PPC }\end{array}$ & $\begin{array}{l}\text { Identifying symptoms, } \\
\text { Explaining the influencing factors and the etiology, } \\
\text { Knowing the assessment methods of the symptom, } \\
\text { Discussing pharmacological and non-pharmacological approaches to symptoms, } \\
\text { Determining appropriate nursing interventions toward symptoms }\end{array}$ & $\begin{array}{l}\text { Presentation, Case scenario, In- } \\
\text { class group discussion, Concept } \\
\text { map, QR code application, Nursing } \\
\text { care plan }\end{array}$ \\
\hline $\begin{array}{l}\frac{\hat{0}}{\bar{z}} \\
\frac{\mathrm{g}}{2}\end{array}$ & $\begin{array}{l}\text { Neutropenia- } \\
\text { thrombocytopenia- } \\
\text { anemia, and management } \\
\text { in PPC }\end{array}$ & $\begin{array}{l}\text { Identifying symptoms, } \\
\text { Explaining the influencing factors and the etiology, } \\
\text { Knowing the assessment methods of the symptom, } \\
\text { Discussing pharmacological and non-pharmacological approaches to symptoms, } \\
\text { Determining appropriate nursing interventions toward symptoms }\end{array}$ & $\begin{array}{l}\text { Presentation, Case scenario, In- } \\
\text { class group discussion, Concept } \\
\text { map, QR code application, Nursing } \\
\text { care plan }\end{array}$ \\
\hline $\begin{array}{l}\infty \\
\frac{0}{\Sigma} \\
\frac{0}{2} \\
\sum\end{array}$ & $\begin{array}{l}\text { Skin reactions in PPC and } \\
\text { nursing approach }\end{array}$ & $\begin{array}{l}\text { Identifying symptoms, } \\
\text { Explaining the influencing factors and the etiology, } \\
\text { Knowing the assessment methods of the symptom, } \\
\text { Discussing pharmacological and non-pharmacological approaches to symptoms, } \\
\text { Determining appropriate nursing interventions toward symptoms }\end{array}$ & $\begin{array}{l}\text { Presentation, Case scenario, In- } \\
\text { class group discussion, Concept } \\
\text { map, QR code application, Nursing } \\
\text { care plan }\end{array}$ \\
\hline $\begin{array}{l}\frac{0}{2} \\
\frac{0}{5} \\
\frac{0}{\Sigma}\end{array}$ & $\begin{array}{l}\text { Psychosocial disorders and } \\
\text { management in PPC }\end{array}$ & $\begin{array}{l}\text { Identifying symptoms, } \\
\text { Explaining the influencing factors and the etiology, } \\
\text { Knowing the assessment methods of the symptom, } \\
\text { Discussing pharmacological and non-pharmacological approaches to symptoms, } \\
\text { Determining appropriate nursing interventions toward symptoms }\end{array}$ & $\begin{array}{l}\text { Presentation, Case scenario, In- } \\
\text { class group discussion, Concept } \\
\text { map, QR code application, Nursing } \\
\text { care plan }\end{array}$ \\
\hline $\begin{array}{l}\text { 옹 } \\
\frac{0}{5} \\
\frac{0}{0} \\
\sum\end{array}$ & $\begin{array}{l}\text { Communication with } \\
\text { PPC patient and family - } \\
\text { Interactive Sharing }\end{array}$ & $\begin{array}{l}\text { Learning to establish correct communication techniques with the patient and the family, } \\
\text { Explain the points to be considered in communication }\end{array}$ & $\begin{array}{l}\text { Presentation, Panel with the } \\
\text { parents receiving care in the } \\
\text { related unit }\end{array}$ \\
\hline $\begin{array}{l}\frac{7}{1} \\
\frac{0}{5} \\
\frac{0}{0} \\
\sum\end{array}$ & $\begin{array}{l}\text { Ethical and legal } \\
\text { dimensions of PPC }\end{array}$ & $\begin{array}{l}\text { Ethical considerations in pediatric palliative care, } \\
\text { Legal aspects of pediatric palliative care }\end{array}$ & Presentation, Case scenario, \\
\hline 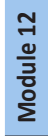 & $\begin{array}{l}\text { Spiritual care of the PPC } \\
\text { patient and the family }\end{array}$ & $\begin{array}{l}\text { Learning the role of the nurse in spiritual care, } \\
\text { Learning cases that may cause spiritual distress in the patient and the family, } \\
\text { Discussing appropriate nursing interventions }\end{array}$ & $\begin{array}{l}\text { Presentation, Case scenario, } \\
\text { Concept map, Nursing care plan }\end{array}$ \\
\hline $\begin{array}{l}\stackrel{m}{1} \\
\frac{0}{5} \\
\frac{\pi}{0} \\
\frac{0}{\Sigma}\end{array}$ & $\begin{array}{l}\text { End-of-life care of the PPC } \\
\text { patient and care of the } \\
\text { family during the grieving } \\
\text { process }\end{array}$ & $\begin{array}{l}\text { Knowing nursing interventions to be implemented before, during, and after death, } \\
\text { Knowing the role and importance of the nurse in family care during the grieving process, Learning } \\
\text { the interventions to be applied to the family during the grieving process }\end{array}$ & $\begin{array}{l}\text { Presentation, Case scenario, } \\
\text { Concept map, Nursing care plan }\end{array}$ \\
\hline 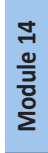 & $\begin{array}{l}\text { Complementary and } \\
\text { alternative medicine } \\
\text { (CAM) applications and } \\
\text { nursing approaches in PPC }\end{array}$ & $\begin{array}{l}\text { Purpose of CAM in pediatric palliative care, } \\
\text { CAM methods used in pediatric palliative care }\end{array}$ & $\begin{array}{l}\text { Presentation, In-class group } \\
\text { discussion }\end{array}$ \\
\hline
\end{tabular}


Table 2 presents the comparison of mean total scores of nursing students in the intervention and control group for the PCKLQ, and the PCSPS and the FATCOD Scale. Multidimensional variance analysis was used in repeated measurements to determine whether there were any differences between the groups' total mean scores on the PCKLQ, PCSPS and FATCOD. Statistically significant differences were found between the mean scores, respectively $(F=48.961, p=0.000 ; F=14.809$, $p=0.000 ; F=84.756, p=0.000)$.

Table 3 presents the relationship between the education program and palliative care practices, PCKLQ and FATCOD. A high level, positive, and highly significant relationship was found between the education program and PCKLQ, FATCOD, and PCSPS $(p<0.01)$.

Table 4 presents the difference in the level of attitudes with respect to nursing students' PCKLQ, their practices, and FATCOD. While the education program was found to explain
$83 \%$ of the increase in the level of PCKLQ ( $R 2=0.832)$, getting education was observed to increase the level of PCKLQ by 0.912 times $(\beta=0.912)$. Moreover, the education program explained $87 \%(R 2=0.877)$ of the increase in the level of PCSPS, getting education increased the PCSPS by 0.936 times $(\beta=-0.936)$. Besides, while the education program explained $95 \%$ of the increase in the level of FATCOD (R2 $=0.955$ ), getting education increased the FATCOD by 0.977 times ( $\beta$ $=-0.977$ ). $\mathrm{PPC}$ education program was determined to be statistically significant in increasing nursing students' PCKLQ, PCSPS, and FATCOD $(p<0.001)$.

The power and effect size of the study was evaluated according to the regression analysis. The power of the study for the Palliative Care Knowledge Questionnaire was 0.99, and the effect size $\left(f^{2}\right)$ was 0.846 . The power for the PCSPS was 0.99 , and the effect size $\left(f^{2}\right)$ was 0.880 . Moreover, for the FATCOD Scale, the power of the study was 0.99, and the effect size $\left(\mathrm{f}^{2}\right)$ was 0.960 .

Table 2. Comparison of Mean Total Scores of Nursing Students in the Intervention and Control Group for Palliative Care Knowledge Level Form and the Scale of Self-Reported Palliative Care Practices

\begin{tabular}{|c|c|c|c|c|c|}
\hline $\begin{array}{l}\text { Time } \\
\text { Group }\end{array}$ & & $\begin{array}{c}\text { Pretest } \\
X \pm S S\end{array}$ & $\begin{array}{c}\text { Posttest } 1 \\
X \pm S S\end{array}$ & \multicolumn{2}{|c|}{$\begin{array}{c}\text { Posttest } 2 \\
X \pm S S F p\end{array}$} \\
\hline \multirow[t]{2}{*}{ PCKLQ } & Experimental group & $27.35 \pm 10.65$ & $60.58 \pm 6.87$ & $59.00 \pm 5.45$ & \\
\hline & Control group & $25.59 \pm 9.96$ & $27.04 \pm 9.73$ & $27.45 \pm 9.81$ & 48.9610 .000 \\
\hline \multirow[t]{2}{*}{ PCSPS } & Experimental group & $28.58 \pm 9.13$ & $73.70 \pm 8.65$ & $72.82 \pm 9.16$ & \\
\hline & Control group & $28.50 \pm 8.45$ & $29.72 \pm 8.59$ & $29.72 \pm 8.59$ & 14.8090 .000 \\
\hline \multirow[t]{2}{*}{ FATCOD } & Experimental group & $46.47 \pm 18.00$ & $147.29 \pm 16.13$ & $143.82 \pm 11.66$ & \\
\hline & Control group & $45.90 \pm 17.83$ & $47.22 \pm 16.82$ & $48.54 \pm 17.50$ & 84.7560 .000 \\
\hline
\end{tabular}

PCKLQ: Palliative Care Knowledge Level Questionnaire; PCSPS: the Palliative Care Self-reported Practices Scale; FATCOD: the FATCOD Scale

Table 3. The Relationship between Study Variables

\begin{tabular}{l|c|c|c|c}
\hline & $\mathbf{2}$ & & $\mathbf{3}$ \\
1. The Palliative Care Self-reported Practices Scale & 1.000 & & \\
\hline 2. The Frommelt Attitudes Toward Care of the Dying Scale & 0.942 & 1.000 & & \\
\hline 3. The Palliative Care Knowledge Level Questionnaire & 0.971 & 0.933 & 1.000 & \\
\hline 4. Training & 0.936 & 0.977 & 0.912 & 1.000 \\
\hline
\end{tabular}

*Significant at $p<0.01$.

Table 4. The Extent to which the Education Predicted the Difference in Palliative Care Knowledge Level, Practices, and Attitudes toward Providing Care to the Dying according to the Self-Evaluation of the Nursing Students

\begin{tabular}{|c|c|c|c|c|c|c|c|c|c|c|c|c|c|c|c|}
\hline \multirow[t]{2}{*}{ Variable } & \multicolumn{5}{|c|}{ Palliative care knowledge level } & \multicolumn{5}{|c|}{ Palliative care self-reported practices } & \multicolumn{5}{|c|}{$\begin{array}{c}\text { Attitude toward providing care to the } \\
\text { dying }\end{array}$} \\
\hline & B & SH & $\beta$ & $\mathrm{t}$ & $p$ & B & SH & $\beta$ & $t$ & $p$ & B & SH & $\beta$ & $t$ & $p$ \\
\hline Study* & 32.781 & 2.419 & 0.912 & 13.551 & 0.000 & 43.890 & 2.704 & 0.936 & 16.234 & 0.000 & 99.505 & 3.546 & 0.977 & 28.062 & 0.000 \\
\hline $\mathbf{R}$ & \multicolumn{5}{|c|}{0.912} & \multicolumn{5}{|c|}{0.936} & \multicolumn{5}{|c|}{0.977} \\
\hline $\mathbf{R}^{2}$ & \multicolumn{5}{|c|}{0.832} & \multicolumn{5}{|c|}{0.877} & \multicolumn{5}{|c|}{0.955} \\
\hline$F$ & \multicolumn{5}{|c|}{183.607} & \multicolumn{5}{|c|}{263.536} & \multicolumn{5}{|c|}{787.491} \\
\hline $\mathbf{P}$ & \multicolumn{5}{|c|}{0.000} & \multicolumn{5}{|c|}{0.000} & \multicolumn{5}{|c|}{0.000} \\
\hline
\end{tabular}

*When coding the study program, the intervention group was coded as " 1 " and the control group as " 0. " 


\section{DISCUSSION}

The present research found statistically important variations between the cumulative scores of the experimental and control groups on the PCKLQ and PCSPS; the experimental group's post-test mean scores were higher than their pretest mean scores (Table 2). In the literature, there are studies examining the effects of education models on nursing students' level of adult PCKLQ and PCSPS $(11,12)$. However, literature reports limited studies investigating the effect of education models on nursing students' PCKLQ and PCSPS C. However, there were studies in the literature examining how interactive education models affect nursing students' level of PCKLQ and PCSPS $(13,14)$. In nursing education, especially, interactive education models such as group discussion, and concept maps have been reported to help students understand the subject, reinforce learning, and ensure the permanence of information $(13,15)$. Besides, case discussions and nursing care plan sharing are emphasized to help students use the knowledge to real-life (clinical practice, case-studies etc.) and enable them to grasp how to transfer theoretical knowledge into practice (16). In the literature, web-based PPC education was found effective in increasing PCKLQ and PCSPS (3). In addition, it determined that palliative care education provided to nursing students via videos, case studies, and role-play methods increased the knowledge level and practices of students in the literature (17). The findings of the literature were observed to be consistent with those of the study. In the current study, provision of PPC information to students, conduction of case discussions using case scenarios, discussion of students' questions through group discussions, and the ease of student access to related materials were thought to be effective in increasing PCKLQ and PCSPS levels and post - education mean scores of the experimental group.

This study found statistically significant differences between experimental and control groups' total scores on the FATCOD, the post-test mean scores of the experimental group were higher than their pre-test mean scores and control group scores (Table 2). In the literature, there was no study examining the effect of PPC education applied to the nursing students on their FATCOD. However, there exist studies in the literature examining how education provided through interactive education methods affected nursing students' attitudes and anxieties toward death $(4,5)$. In a study, interactive methods, such as case scenarios, concept map group work, and simulation, were stated to be employed in teaching how to provide care to the dying in nursing undergraduate education (12). In a study with nursing students, it determined that during palliative care education, case scenarios and interactive education methods provided an experimental opportunity in reducing students' anxiety about dying child (14). Another study emphasized that it was important for students to feel comfortable about providing care to the child who is dying; moreover, using several education methods to orient students to this situation was effective (5). The availability of palliative care education in undergraduate nursing education and the use of interactive education methods while teaching are emphasized to be significant in developing nursing students' PPC practices and effective clinical decision-making skills while caring for the dying child $(4,5)$. The findings of the literature were consistent with those of the study. In the present study, discussion of care during the death and grieving process with methods, such as case scenarios, in-group discussions, were believed to positively affect students' attitudes. Furthermore, in the interview modules with a nurse working in the PPC unit and a parent whose child was receiving palliative care, the attitude scores of the students were believed to increase because students asked questions and joined group discussions by sharing their anxieties about providing care to a dying child.

In the current study, a high level, positive, and highly significant relationship was found between the education program and the PCSPC, the FATCOD Scale, and the PCKLQ (Table 3, $p<$ 0.01 ). The education program explained $83 \%$ of the increase in the level of PCKLQ, $87 \%$ of the increase in the level of PCSPS, and $95 \%$ of the increase in the level of FATCOD (Table 4). While there are limited data in the literature regarding what percentage of changes in the level of PCKLQ and PCSPS levels were affected by PPC education programs (3), there was no information on the extent of change in attitude level related to providing care to the dying. When we examined literature revealing changes in the PCKLQ and PCSPS level brought about by PPC education programs, web-based education was found to be effective in increasing palliative care knowledge levels and practices (3). Moreover, several factors have been reported in the literature that affect both palliative care knowledge and practices including attitudes toward giving care to the dying $(18,19)$. Therefore, the finding that the education program provided $83 \%$ increase in PCKLQ level of nursing students, $87 \%$ increase in their level of PCSPS, and $95 \%$ increase in their attitudes toward providing care to the dying suggested a good outcome in terms of PCKLQ and practices, which are affected by several factors, and in terms of caring for the dying. Furthermore, this finding reveals the effectiveness of the study. The effectiveness of the education program is believed to stem from the fact that it focused on nursing students; it covered all topics related to PPC; it included information about psychosocial areas such as spiritual care, death, and grieving in the context of PPC; it employed interactive learning methods; the content of the education centered on the learning needs of the nursing students, and it was nursing care plan-oriented.

The power and effect size were calculated according to the regression analysis. The study was found to be powerful in terms of both the level of PCKLQ, PCSPS and FATCOD. While the power shows the statistical significance of the study, the effect size provides information about practice/clinical significance (20). According to literature classification of effect sizes (f2), $0.02 \geq \mathrm{f} 2<0.15$ implies small effect size, $0.15 \geq \mathrm{f} 2<0.35$ implies a medium effect size, and $0.35 \geq$ implies a large effect size (20). Considering these values, the present study was observed to have a large effect size in all dimensions. In literature, studies indicating the power and effect size of education programs related to PPC are 
limited (3). In the study of Kudubeş and Bektaş (2019), the web-based PPC education program was determined to have a small effect size for palliative care knowledge level and large effect size for palliative care practices. In the present study, the effect size for all variables was greater than 0.80 , which indicated that the application significance of the study was high. The application significance of the face-toface interactive education conducted with nursing students was believed to be higher than that of the web-supported education method. These results revealed that the study was feasible and effective.

\subsection{Limitations}

The investigators developed the PCKLQ used in the analysis. To ensure the reliability and authenticity of the assessment form, expert opinions were collected and the material validity index was determined.

\section{CONCLUSION}

In conclusion, it was found that the PPC education curriculum was successful in enhancing the skills and activities of nursing students and their constructive attitudes towards the treatment of the dying infant, adding to the literature and nursing education of the nation and world. This study showed that the PPC education program could be effectively used in educating nursing students. Furthermore, assessment of cognitive and psychomotor skills and conducting future clinical evaluation studies that include PPC education programs would provide clearer results.

Acknowledgement: We would like to thank all the participants.

Conflicts of Interests Statement: The authors have no funding or conflicts of interest to disclose. The authors have no conflicts of interest to disclose.

Funding: The authors received no financial support for the research, authorship, and/or publication of this article.

\section{REFERENCES}

[1] Snaman JM, Baker JN, Ehrentraut JH, Anghelescu DL. Pediatric oncology: Managing pain at the end of life. Pediatric Drugs 2016; 18(3):161-180.

[2] Snaman, McCarthy S, Wiener L, Wolfe J. Pediatric palliative care in oncology. J Clin Oncol 2020; 20;38(9):954-962.

[3] Akdeniz Kudubes A, Bektas M. The effect of web-based pediatric palliative care education on the palliative care knowledge level and practices of nursing students. Perspect Psychiatr Care 2019;15: 12463.

[4] Stayer D, Lockhart JS. Living with dying in the pediatric intensive care unit: A nursing perspective. Am J Crit Care 2016;1;25(4):350-356.
[5] Grimston M, Butler AE, Copnell B. Critical care nurses' experiences of caring for a dying child: A qualitative evidence synthesis. J Adv Nurs 2018;1:74(8):1752-1768.

[6] Bhatnagar S, Patel A. Effectiveness of the certificate course in essentials of palliative care program on the knowledge in palliative care among the participants: A cross-sectional interventional study. Indian J Palliat Care 2018;1;24(1):86-92.

[7] Akard TF, Hendricks-Ferguson VL, Gilmer MJ. Pediatric palliative care nursing. Ann Palliat Med 2019;8(1):S39-48.

[8] Kudubes AA, Bektas M, Ayar D, Bektas I, Selekoglu Ok Y, Sal Altan S. Palliative Care Difficulties and Psychometric Properties of the Turkish Version of the Self-Esteem Based Palliative Care Practice Scale. Int J Caring Sci 2019;12(1):162-175.

[9] Nakazawa $Y$, Miyashita M, Morita T, Umeda M, Oyagi $Y$, Ogasawara T. The palliative care self-reported practices scale and the palliative care difficulties scale: Reliability and validity of two scales evaluating self-reported practices and difficulties experienced in palliative care by health professionals. J Palliat Med 2010;1:13(4):427-437.

[10] Cevik B, Kav S. Attitudes and experiences of nurses toward death and caring for dying patients in Turkey. Cancer Nurs 2013;36(6):E58-65.

[11] Hermann CP, Head BA, Black K, Singleton K. Preparing nursing students for interprofessional practice: The Interdisciplinary curriculum for oncology palliative care education. J Prof Nurs. 2016;1;32(1):62-71.

[12] Randall D, Garbutt D, Barnard M. Using simulation as a learning experience in clinical teams to learn about palliative and end-oflife care: A literature review. Death Stud 2018;42(3):172-183.

[13] Santos J, Figueiredo AS, Vieira M. Innovative pedagogical practices in higher education: An integrative literature review. Nurs Edu Today 2019; 72:12-17.

[14] Moody K, McHugh M, Baker R, Cohen H, Pinto P, Deutsch S. Providing Pediatric palliative care education using problembased learning. J Palliat Med 2018;21(1):22-27.

[15] Milner KA, Cosme S. The PICO Game: An Innovative strategy for teaching step 1 in evidence-based practice. Worldviews Evidence-Based Nurs 2017;14(6):514-516.

[16] Sharafi S, Chamanzari H, Pouresmail Z, Rajabpour M, Bazzi A. The Effect of case method and primary nursing method on the social dimension in quality of patient care. J Holist Nurs Midwifery 2018; 28(4):252-258.

[17] Mastroianni C, Ramon Codina M, D’Angelo D, Petitti T, Latina R, Casale G. Palliative Care education in undergraduate nursing curriculum in Italy. J Hosp Palliat Nurs 2019;21(1):96-103.

[18] Chan RJ, Webster J, Bowers A. End-of-life care pathways for improving outcomes in caring for the dying. Cochrane Database of Systematic Reviews 2016; 14651858.

[19] Henoch I, Melin-Johansson C, Bergh I, Strang S, Ek K, Hammarlund $\mathrm{K}$, et al. Undergraduate nursing students' attitudes and preparedness toward caring for dying persons A longitudinal study. Nurse Educ Prac. 2017;26:12-20.

[20] Albers C, Lakens D. When power analyses based on pilot data are biased: Inaccurate effect size estimators and follow-up bias. J Exp Soc Psychol 2018;74:187-195. 